\title{
LA ICONICIDAD ANAGRAMÁTICA Para una versión peirceana de la hipótesis anagramática de Saussure
}

\author{
Ángel Herrero Blanco
}

Universidad de Alicante

Si la hipótesis anagramática ensayada por Saussure en los Cahiers, tal como fue siendo conocida y discutida a partir de su publicación parcial por Jean Starobinski (1971) ${ }^{1}$, puede aún sostenerse e, incluso, como se ha afirmado, abrir expectativas teóricas para una lingüística de la literatura, no será sino con la cautela de reducirla al dominio de lo figural, esto es, considerando el anagrama como un procedimiento general de creación de lenguaje, más o menos recurrente, aunque fundamental en los casos de su efectiva ocurrencia en los textos poéticos, y no, tal como pretendió Saussure, como un principio universal de la inspiración poética. A la hipótesis así considerada la llamaremos hipótesis anagramática reducida.

1 El libro de Starobinski espera aún una edición crítica y una traducción correcta al español. Para un estudio detallado del proceso de recepción y crítica de los Cahiers, véase Rodríguez (1997). 
Sin embargo, la belleza del atrevimiento teórico de Saussure no dejará de cautivarnos por su propia rareza, por la imagen que nos procura de un Saussure al fin y al cabo insólito: no por buscar sistemas, claro está, sino por hacerlo allí donde parece dominar el genio, la excepción, la iluminación. En las páginas que siguen trataré de justificar el fracaso de Saussure por los límites mismos de su semiología, anclada en la noción de signo binario y diferencial, y de propiciar un rescate de la hipótesis (reducida) mediante la consideración de la semiótica peirceana, que puede, desde mi punto de vista, ubicar la pulsión anagramática en la semiótica del arte y explicar su valor en los textos. Esta esperanza descansa en los desarrollos que la semiótica peirceana ha promovido en el campo de la lingüística de lo no arbitrario: el paradigma sustancialista defendido por Raffale Simone (1990), el naturalista Wolfgang U. Dressler (1990), etc. La generalización del concepto peirceano de iconicidad, alimentado por las riquísimas observaciones sobre el lenguaje de Ludwig Wittgenstein -que son fuente también del paradigma sustancialistanos permite tratar el anagramatismo como un fenómeno en cierto modo natural.

El límite al que me he referido, relativo a la noción diferencial del signo en Saussure, chocaba de lleno con su hipótesis de la génesis anagramática de la poesía. Lo diferencial suponía una definición negativa del signo, mientras que la diseminación anagramática se mostraba como un exceso, una insólita plenitud combinatoria de los signos. Siendo esto fundamental para entender el abandono o el aplazamiento de la hipótesis por el maestro, hay que decir inmediatemente que, sin embargo, en varias ocasiones, aún dentro del Cours, Saussure se deslizó hacia esta positividad de los signos fónicos; así, en el tercer curso (Engler 1911FF), escribe:

Grâce à ce que les différences se conditionent les unes les autres, nous aurons quelque chose pouvant resembler à des termes positifs par la mise en regard de telle différence de l'idée avec telle différence du signe. On pourra alors parler de l'opposition des termes et donc ne pas maintenir qu'il n'y a que des différences à cause de cet élément positif de la combinaison.

La positividad de los signos no descansa sólo en esta combinatoria efectiva de los elementos diferenciales; gracias a ella, y a la divisibilidad temporal de la cadena sonora, se crean lo que en una nota recogida por Rudolf Engler [3317.2] llama Saussure pseudo-organismos: 
Item. Fait que le mot n'est pas assez long pour qu'il ne soit possible de le recolliger dans une seule sensation. C'est là concuremment à la divisibilité temporelle ce qui en fait un pseudo-organisme si puissant d'illusions.

Como precisó Engler (1994:41-42) a propósito de estas referencias, «the terms illusion and pseudo-organisme may appear to be negative, but they are not. It is important to bear in mind that psychologization involves entering the field of the speaker's consciousness and this, we know, is the fundamental principle of synchrony», de modo que «from the synchronic point of view iconicity has the pre-eminent place, even to the point of calling into question the arbitrary nature of the linguistic sign», del signo saussureano. Este punto de vista sincrónico del hablante es el que la psicosistemática desarrolló mediante su noción de la significancia. Sin embargo, sólo en la semiótica de Peirce se le reconoce a la iconicidad un valor semiótico universal, porque la semiosis se concibe fenomenológica y no sistemáticamente. Parece plausible esperar que las intuiciones de Saussure sólo laterales en el Cours pero centrales en los Cahiers encuentren en la semiótica de Peirce, a través de la noción clave de iconicidad, el marco teórico y la generalización que allí les faltaba.

Si el signo es para Saussure pura negatividad, el icono o representamen icónico peirceano, dimensión del signo en la Primariedad o Posibilidad, es una cualidad eminentemente positiva: «An Icon is a Representamen which fulfills the function of a representamen by virtue of a character which it possesses in itself, and would would possess just the same though its object did not exist» (C.P., 5.73). El icono es «an Originalian sign, which is a sign whose significant virtue is due simply to its quality. Such, for example, are imaginations of how I would act under certain circumstances» (2.92). Pero la iconicidad es una dimensión universal de los signos, y está presente en todos los fenómenos: «There is a point of view from which the whole universe of phenomena appears to be made of nothing but sensitive qualities. What is that point of view? It is that in which we atend to each part as it appears in itself, in its own suchness, while we disregard the connections» (1.422). Y, por fin, «An Icon is a Representamen os what it represents and for the mind that interprets it as such, by virtue of its being an inmediate image, that is to say by virtue of characters which belong to it in itself as a sensible object, and which it would possess just the same were there no object in nature that it resembled, and though it were never interpreted as a sign. It is of the nature of an appearence, and as such, strictly speaking, exists only in consciousness» (4.447). 
Frente a la diferencia saussureana como negatividad, el icono peirceano se muestra como una positividad indiferente, o, como señaló Rossella Fabbrichesi (1983) en su importante estudio sobre la polémica de la iconicidad «una sempre differita identità, in un luogo nel quale identità e differenza sono lo stesso». Dejando al margen el carácter diferido - que no compartimos», la indiferencia se da como relación del representamen icónico y su objeto, que no se relacionan por una relación estrictamente de semejanza entre dos elementos individuados (criterio que, como señaló Douglas Greenlee (1976), conduce a consecuencias absurdas, pues todo se parece a algo en algún aspecto), sino por coparticipar de una forma, que es el ground de la relación. Peirce se refirió al criterio de semejanza para invertir los términos del problema con extraordinaria lucidez: «[...] inner association is commonly called association by resemblance; but in my opinion it is not the resemblance which causes the association, but the association which constitues the resemblance» (C.P. 4.157 y 1.383), y dejó acerca de esta indiferencia entre representamen y objeto una observación memorable, referida precisamente al arte pictórico: «In contemplating a painting, there is a moment when we lose consciousness that it is a thing. The distinction between the real and the copy desappears, and is, for the moment, pure dream. Not any particular existence, yet, not general. At that moment we are contemplating an Icon» (3.362).

Esta categoría de fenómenos, los iconos, que Peirce caracterizó como «ideas of feeling» (4.157) - frente a los índices («acts of reaction») y a los símbolos («habits») - suponen por lo tanto formas semiogenéticas $^{2}$. El objeto del icono será llamado por Peirce Kalos, cualidad inmediatamente persuasiva que se encarna en el signo icónico como una diferencia interna, para emplear un término de R. Fabbrichesi. No es que el signo icónico carezca de objeto, es que su objeto no es un existente, ni una clase de existentes, sino una cualidad que el icono toma como semiosis. Esto es importantísimo para no reducir la pulsión icónica, y concretamente la anagramática, a un juego de sustituciones. Un anagrama, en el sentido de Saussure, no tiene como objeto al nombre que el texto disemina, sino la cualidad de la que ambos participan y que propone un interpretante emocional, en términos de Peirce.

Pero volvamos a la última observación de Peirce acerca de la contemplación de la pintura, para retomar la cuestión anagramática en el

2 Para el estudio de las tres dimensiones de representamina, Hocutt (1960). La icogénesis puede ser estudiada en Uexküll (1986) y en Ransdell $(1969,1986)$. 
campo de los fenómenos reales que interesaron a Saussure, el de los textos poéticos. Hay un poema ${ }^{3}$ en el que el poeta, Manuel Machado, contemplando o, mejor, recordando la emoción de haber contemplado (evocando con la memoria el sueño, diría su hermano Antonio) un cuadro de Velázquez cuyo título seguramente equivoca, nos describe a la Infanta Margarita de la mano del pintor, cuyo nombre aparece al final del poema con bastante evidencia, haciéndose lo mismo que describe, es decir, firmando cuadro y poema. Está incluido en Apolo. Teatro pictórico, de 1911:

\begin{abstract}
Como una flor clorótica el semblante, que hábil pincel tiño de leche y fresa, emerge del pomposo guardainfante, entre sus galas cortesanas presa.
\end{abstract}

La mano - ámbar de ensueño- entre los tules de la falda desmáyase, y sostiene el pañuelo riquísimo, que viene de los ojos atónitos y azules.

Italia, Flandes, Portugal... Poniente sol de la gloria, el último destello en sus mejillas infantiles posa...

Y corona no más su augusta frente la dorada ceniza del cabello

QUE apenas prende el leVE LAZo rosa.

Aquí el poeta ha reproducido la experiencia icónica de su evocación, y el nombre del pintor se anagramatiza con naturalidad (a pesar la carencia gráfica de una «Z», pero manteniendo el acento que centraliza la palabra), identificado con el detalle que remata el poema y el cabello de la infanta. La cualidad que el texto muestra y que se concentra en ese detalle final es la cualidad asociada al nombre de Velázquez. Diríamos que el poeta, y con él el lector, experimenta en la descripción del cuadro recordado la emoción de haber captado el espíritu del pintor, y la diferencia entre el original de esa emoción (Velázquez) y la copia (el poema, clausurado en ese verso final) tiende a desaparecer.

${ }^{3}$ Debo este ejemplo a la pericia de Jaime Climent, alumno en la Universidad de Alicante. 
Que un texto reproduzca un nombre no es en casos como éste cuestión de juego de palabras. Entre el poema como fábula (como conjunto de hechos o de descripciones) y el nombre debe haber una relación que, como se ha señalado, consiste en una cualidad. ¿Cómo podemos entender la pertinencia de esta relación?, ¿qué la motiva? Para responder a estas preguntas, propongo considerar la cuestión anagramática primero en el marco de la iconicidad general del lenguaje, $y$, dando un paso más, como la iconicidad que promueven algunos nombres propios.

Como hemos apuntado al principio, la naturaleza profundamente icónica del lenguaje está siendo un postulado fundamental en el paradigma sustancialista que, arrancando de Leibniz y de Vico, y recogiendo la concepción diagramática del lenguaje de Wittgenstein (Simone, 1994: 158), construye una lingüística de lo no-arbitrario. Se trata de concebir el lenguaje, en su empleo discursivo habitual, no como mera representación convencional de hechos, sino, siguiendo a Wittgenstein, como conjunto de hechos en sí mismos ( «Das Stazzeichen ist eine Tatsache», Tractatus, 3.14); hechos de cuyos componentes, las palabras, puede afirmarse que están combinados en la forma que describe la gramática, pero también que sólo en la medida en que, constituyendo oraciones, las palabras son hechos, «they exhibit likeness with facts proper», escribe Raffaele Simone (1994:155), de modo que «to some extent sentences and states of affairs may be interchangeable for they have te same structure». Si ahora incluimos entre los hechos al propio lenguaje, especialmente esos nombres en los que se espesa un conjunto valioso de experiencias psíquicas o morales, de experiencias normativas, podremos ya entender que el anagramatismo es un caso de recursividad, un bucle del lenguaje.

Pero el anagrama no se aplica indiscriminadamente. La cuestión, y la explicación decisiva de esta selección anagramática, la plantea Simone (1994:160) en los términos siguientes: «Is there in language any deeply rooted need for diagrammatic utterances? or are they to be considered as a sheer accident in language structure? The idea I want to propose here is that there is such a need and that it is pragmatic in nature: some types of utterances performs tasks which are so specific that they cannot be performed by other types of utterances equally well. If so, there must be some specific classes of actions which could not be performed if not having iconic or diagrammatic utterances at one's disposal».

Esto es especialmente claro en el caso de las acciones sagradas, y en general en toda aquella experiencia dominada por la admiración, por 
la saliencia de aquello que la produce y a la que se refiere. En este carácter liminar de la iconicidad coincidieron también Peirce y Wittgenstein, precisamente acerca de la experiencia de lo bueno o bello. Basta comparar la Wittgenstein's Lecture on Ethics con esta afirmación de las Lectures on Pragmatics de Peirce: «But we cannot get any clue to the secret of Ethics [...] until we have first made up our formula for what it is that we are prepared to admire» (C.P. 5.36). Al fin, lo admirable inmediato, lo cualitativo como experiencia, lleva a lo inefable, a los límites del lenguaje, allí donde el lenguaje necesariamente falla para mostrar la saliencia de lo admirable. Wittgenstein lo expresaba con nitidez: «Un característico mal uso de nuestro lenguaje subyace en todas las expresiones éticas y religiosas. Todas ellas parecen, prima facie, ser sólo símiles [...] veo ahora que estas expresiones carentes de sentido no carecían de sentido por no haber hallado aún las expresiones correctas, sino que era su falta de sentido lo que constituía su mismísima esencia» (1981: 40-43).

Pero los límites del lenguaje son fluidos; entre lo común y lo saliente hay una relación estrecha. El lenguaje entero se mueve entre esos dos polos. El orden de palabras y de oraciones, las relaciones de causalidad, de distribución, de subrogación, etc., que se manifiestan en los textos resultan fenómenos de iconicidad diagramática entre el lenguaje y la realidad referida. Hay en el lenguaje una iconicidad ya convertida en hábito, en hipoiconicidad. ¿Cómo se sitúa el anagrama en esta dimensión icónica del lenguaje?, ¿hasta qué punto la pulsión anagramática es una pulsión lingüística?

Peirce habló, siguiendo su modelo ternario, de tres tipos de iconos, que debemos considerar como tres grados de iconicidad: las imágenes, las metáforas y los diagramas; es decir, iconos cualitativos o potenciales, efectivos o accidentales, y habituales o convencionales. Los extremos de este gradiente se pueden hacer coincidir con dos dominios típicos del lenguaje, tal como lo entendió (Hocutt 1962: 158): los diagramas o grafos -iconos basados en la similitud de estructura con los hechos-se desarrollan en el ámbito de las ciencias que requieren matematización y en el ámbito del lenguaje como expresión del pensamiento científico; las imágenes -iconos basados en la cualidad-, son los propios del arte. El signo estético es un icono cuyo objeto es una cualidad o Kalos, y cuyo interpretante es el interpretante emocional. La experiencia icónica es más un reconocimiento que una ideación, pero no por ello es menos convincente: «Aquello de lo que estoy seguro —escribía Wittgenstein-, no lo he aprendido expresamente, 
sino que lo encuentro más tarde como eje de rotación de un cuerpo en movimiento» (Brand 1981: 21). De ahí que el momento de la experiencia icónica como evidencia deviene el momento fundamental de la fruición estética; evidencia de que el icono es la forma de la emoción que el artista pretendía proponernos, y que nos alcanza a través de ella. El signo matemático, por el contrario, propone un interpretante lógico.

Pero estos extremos son dimensiones, no tipos diferenciales. La diagramaticidad puede ser tan inconsciente como efectiva, y muchas de las observaciones de Wittgenstein apuntan, me parece, en esta dirección. La iconicidad se da entre hechos que son extralingüísticos y hechos lingüísticos, pero también entre cualidades, sin que ambos dominios se excluyan; al contrario, se implican. Wittgenstein realizaba la observación anterior a propósito de una imagen, la de una puerta; en otro momento, ante la de una suerte de artefacto mecánico, comenta: «Es como si alguien dijera: ese movimiento se produce tan fácilmente como si hubiera sido ensayado. Y no es que yo compare el objeto con una figura que esté a su lado, sino como si él se cubriera con la figura» (Brand, 1981: 40). La interpretación icónica de una imagen es el mero reconocimiento de la cualidad con la que se cubre. G. Brand comentó esta afirmación con las siguientes palabras: «Es importante darse cuenta de que aquí algo se desdobla inmediatamente de sí mismo, y justamente en un sistema que, como tal sistema, no sale a la luz, y se expresa en ese desdoblarse». Difícilmente habríamos encontrado definición más exacta del anagrama saussuriano por excelencia, el de un nombre omitido y al tiempo emitido en su diseminación poética.

En el poema de M. Machado el nombre de Velázquez se diseminaba en aquel «leve lazo (que...) ». Como en las famosas Meninas, el pintor se deja ver entre las figuras y las pinceladas, ante las palabras que definen su estilo.

Voy a dar otro ejemplo de anagrama muy próximo, tanto en el tiempo como en el procedimiento. Por cierto, que entre uno y otro media el período de tiempo durante el cual precisamente Saussure estudiaba su hipótesis; se trata del siguiente soneto de Rubén Darío, de El canto errante (1907), titulado con el verso que cierra la mayoría de las estrofas, «La bailarina de los pies desnudos»:

Iba en un paso rítmico y felino a avances dulces, ágiles o rudos, con algo de animal y de divino, la bailarina de los pies desnudos. 
Su falda era la falda de las rosas, en sus pechos había dos escudos... Constelada de casos y de cosas... La bailarina de los pies desnudos.

Bajaban mil deleites de los senos

hacia la perla hundida en el ombligo, e iniciaban propósitos obscenos azúcares de fresa y miel de higo.

A un lado de la silla gestatoria estaban mis bufones y mis mudos... ¡Y era toda Selene y Anactoria la bailarina de los pies desnudos!

El poeta reconoce a la bailarina por su descripción característica (del intérprete se requiere, como en el caso del soneto de Manuel Machado, conocer al personaje, haber al menos oído algo de él o haberse hecho una idea, algo que el texto dice, y saber su nombre). La descripción, que se repite al final de las dos primeras estrofas, se hace revelación en los dos versos finales de la última. Entre los dos se lee fácilmente el nombre de la bailarina, Isadora Duncan:

\section{anac oria \\ d nudos \\ ISADORA \\ DUNCAN}

El mismo título y los versos recurrentes encierran el nombre de la bailarina (a falta de una $\langle\mathrm{c} \gg$ ), en lo que viene a ser su descripción definida característica:

la bailarina de los pies desnudos

IS
A
D O

RA

AN

DUN 
La iconicidad diagramática y la que vamos a llamar iconicidad estética son siempre fluidos. Mi propuesta es que el anagrama se sitúa entre ambos, conociendo formas matematizadas (el acróstico, por ejemplo) y formas cualitativas, calológicas (el anagrama saussureano). En los dos sonetos citados hay, junto a lo eminentemente cualitativo, un aspecto claramente formal o diagramático: el nombre aparece como epifonema, como clausura; en los versos finales que encierran el anagrama se consuma el reconocimiento por parte del poeta.

Con todo, lo característico del icono anagramático es que su composición no es resultado de sus partes formalizables, como lo es el acróstico. Peirce atribuyó precisamente a los iconos estéticos esta propiedad, su carácter originariamente compuesto pero al tiempo simple (CP. 1.532), por el que un conjunto de partes se relacionan hasta el punto de impartir una positiva y simple cualidad.

Estamos, pues en estos ejemplos del tenor de los que tentaban a Saussure, ante una iconicidad que se presenta como diagrama poético, en cierto modo libre del rigor de los diagramas matemáticos, porque oscila entre límites más amplios que los de la predicación, pero que, como aquéllos, se basa en la relación de 'diferida identidad' propia de lo icónico: identidad como coparticipación del objeto y del representamen en las propiedades exhibidas por éste en tanto características de aquél, desveladas por el poeta. Como en el anagrama saussureano, el objeto es un individuo célebre, un nombre propio; pero, si su iconicidad no se puede someter a la regla de un grafo (como sí ocurre, por ejemplo, en los acrósticos o en los anagramas comerciales), es porque el objeto del icono no es el nombre sino los hechos o propiedades que se le asocian. Si estas propiedades fueran simples, entonces bastaría con una onomatopeya, o llegaríamos a ver el nombre propio como onomatopeya.

Lo cualitativo como Kalos es una mera posibilidad, independiente de la existencia de un objeto particular y de un intérprete. El referente del nombre propio anagramatizado es ya un ser de leyenda, y por eso se anagramatiza: se ha convertido en cualidad. Frente a los nombres propios especializados en una cualidad característica, y que pueden funcionar, por lo tanto, como un sustantivo casi abstracto («es un pitágoras»; «no seas don juan», etc.), hay nombres propios cuyo valor resulta más vago, o más complejo. Sobre ellos (sobre su supuesto portador) se cruzan distintas dimensiones, y su particularidad viene dada precisamente por su forma de radiar en ellas, para la experiencia de su encuentro en él. Nombres de lo admirable que parecen tener casi vida 
propia, como si su evocación nos lanzara a asociaciones inesperadas. Así, en los siguientes versos de Antonio Machado, recogidos en su Abel Martín y publicados en la Revista de Occidente en 1931, la evocación parafrástica de Virgilio se ve llevada a una descripción insólita del poeta que lo recoge en sus sílabas:

\author{
¡Bajar a los infiernos como el Dante! \\ ¡Levar por compañero \\ de un poeta con nombre de lucero! \\ ¡Y este fulgor violeta en el diamante!
}

\title{
VI \\ I $\quad \mathrm{G} R \quad \mathrm{OL} \quad \mathrm{I}$
}

(además, puede leerse al final «eneida»).

Los anagramas, como todas las imágenes o iconos de la cualidad, pueden ser más o menos felices, más o menos emocionantes. Pero en todos ellos hay una suerte de saber que crece, por la vinculación de la dispersión fónica con la resonancia semántica, y de la resonancia fónica con la dispersión semántica; una cualidad expresada y así, en la posibilidad, convertida en signo. En el proceso natural de interpretación del texto como signo, el descubrimiento anagramático supone por ello el descubrimiento del sentido genético del texto o de un momento del texto, un sentido que, como los que se asocian a los nombres propios admirables, queda abierto a su propio enriquecimiento. Antonio Machado ha convertido, en el último ejemplo, el nombre del poeta no mencionado en una imagen, una imagen espléndida, imagen de la cualidad que así se le reconoce al poeta latino. Algo parecido ocurría en el ejemplo de su hermano Manuel. En otras ocasiones, el nombre propio inspira no sólo una imagen, sino toda la fábula; es, como el héroe, el hilo conductor de lo relatado. Pero en todo caso el texto anagramático se presenta como su paráfrasis poética. Acaso el poeta siga aspirando al don homérico del hallazgo de epítetos, de cualidades esenciales que parecían haber pasado desapercibidas (la nave hueca, pero también la nube quimérica de A. Machado o el externo muro borgiano). Por lo que atañe al intérprete, descubrir un anagrama es propiciar una interpretación cualitativa, cuya verdad estará en su rendimiento. A ello le puede ayudar, sin duda, una cierta «esperanza 
poética», $o$ al menos la falta de prejuicios que la crítica suele tener ante lo figural; le puede ayudar esa esperanza sobre todo ante poetas que, como los tres aquí recogidos, bebieron en los nombres mitológicos buena parte de su caudal estético y aun ético, de su norma poética ${ }^{4}$.

El descubrimiento de un anagrama cualitativo supone en sí mismo una prueba. En las Bemerkungen über die Grundlagen der Mathematik, Wittgentein hizo observaciones inteligentísimas sobre la imagen-prueba, la imagen autodemostrativa (uno de los ejemplos que aduzca será precisamente el de la inversión de las letras), que intuitivamente reconocemos saber; pero Wittgenstein (1981: 40-56) pregunta: «¿Qué sucedería si, en lugar de "intuición" se dijera "correcto acertar"? Presentaría el valor de la intuición bajo una luz totalmente diferente, pues el fenómeno del acierto es sicológico, pero no lo es el del acierto correcto».

En esas imágenes que creemos reconocer, como en el anagrama de personaje-tema, «la imagen actúa como una prueba [...] Se puede pensar que la prueba es un poema, una obra teatral [...] No sabía cómo sucedería pero vi una imagen y quedé convencido de que pasaría tal y como en la imagen. La imagen me ayuda a predecir [...] No encuentro el resultado, sino que encuentro que lo alcanzo [...] He aquí por qué ver una imagen es más que una experiencia [...] A mí me parece que el efecto de la prueba es hacer que los hombres se arrojen sobre la nueva regla» 5 . Del mismo modo, una vez reconocido un anagrama icónico, difícilmente nos resistiremos a releerlo ya para siempre en el poema y a enriquecerlo con él.

Más que el caudal de unas figuras, lo que caracteriza al lenguaje poético es su poder de figuración del lenguaje mismo. Las llamadas figuras son procedimientos lingüísticos por los que el lenguaje habla, pruebas que nos revelan su verdad, su sentido (a veces, también el sinsentido de sus juegos); entre ellas, el anagrama saussureano ocuparía una posición central, pues viene a ser un cruce de paronimias y de paráfrasis acerca de la cualidad atribuida a un nombre. Paráfrasis de su significancia, paráfrasis poética a través de los parónimos de su significancia.

4 Véase, en cuanto a la formación mitológica de A. Machado y a su poética anagramática, Herrero (1996).

${ }_{5}$ Ésta y las anteriores observaciones de Wittgenstein acerca de las imágenes y de su valor como prueba abductiva han sido comentadas en Herrero (1988: 33-34, 66). 


\section{Referencias bibliográficas}

BRAND, G. (1981). Los textos fundamentales de Ludwig Wittgenstein. Madrid: Alianza Editorial [vers. orig. Die grundlegenden texte von Ludwig Wittgenstein, 1975].

DRESSLER, W. (1990). «The cognitive perspective of "naturalist" linguistic models». Cognitive Linguistics 1, 75-98.

FABBRICHESI, R. (1983). La polemica sull' Iconismo. Nápoles: E.S.I.

GREENLEE, D. (1968). «The similarity of Discernibles». Journal of Philosophy 65.

- (1976). «Peirce's Concept of Sign, further Reflections». Transactions of C.S.Peirce Society 12.

Herrero, A. (1988). Semiótica y Creatividad. La lógica abductiva. Madrid: Palas Atenea.

- (1997). «La sibilación escrita. Anagramatismo en la poesía de Antonio Machado». Bulletin Hispanique 98: 1, 205-219.

HocuTT, M.O. (1962). «The logical Foundations of Peirce's esthetics». Journal of Aesthetics and Art Criticism 21.

PeIRCE, Ch.S. (1965). Collected Papers. Eds. Ch. Hartshorne \& P.Weiss. Cambridge, Mass.: Harvard University Press.

RANSDELl, J. (1969). The epistemic function of Iconicity in Perception. Institute for Studies in Pargmatism, 1.

- (1986). «On Peirce's Conception of the Iconicity Sign». Iconicity. Essays on the Nature of Culture, P. Bouissac, M.Herzfeld \& R.Posner (eds.). Tübingen: Stauffenburg Verlag.

RODRÍGUEZ FERRÁNDIZ, R. (1997). La semiótica anagramática de Ferdinand de saussure. Génesis, crítica y tipología. Tesis doctoral. Alicante: Universidad de Alicante.

STAROBINSKI, J. (1971). Les mots sous les mots. París: Gallimard.

SIMONE, R. (1990). «The body of language. The paradigm of arbitrariness and the paradigms of substance». Présence de Saussure, R.Amacker \& R.Englres (eds.), 121-141. Ginebra: Droz.

- (ed.). (1994). Iconicity in Language. Amsterdam/Philadelphia: John Benjamins Pub. Co.

WitTGENSTEIN, L. (1981). Matemáticas sin metafísica. Caracas: Universidad Central de Venezuela. (Vers. or. Bemerkungen über die Grundlagen der Mathematik, 1956). 